\title{
BMJ Open Referrals to integrative medicine in a tertiary hospital: findings from electronic health record data and qualitative interviews
}

\author{
Kristen H Griffin, ${ }^{1}$ Kent C Nate, ${ }^{2}$ Rachael L Rivard, ${ }^{1}$ Jon B Christianson, ${ }^{2}$ \\ Jeffery A Dusek ${ }^{1}$
}

To cite: Griffin KH, Nate KC, Rivard RL, et al. Referrals to integrative medicine in a tertiary hospital: findings from electronic health record data and qualitative interviews. BMJ Open 2016;6:e012006. doi:10.1136/bmjopen-2016012006

- Prepublication history and additional material is available. To view please visit the journal (http://dx.doi.org/ 10.1136/bmjopen-2016012006).

Received 21 March 2016 Revised 7 June 2016 Accepted 5 July 2016

CrossMark

\footnotetext{
${ }^{1}$ Integrative Health Research Center, Penny George Institute for Health and Healing, Allina Health, Minneapolis, Minnesota, USA ${ }^{2}$ Division of Health Policy and Management, University of Minnesota School of Public Health, Minneapolis, Minnesota, USA
}

Correspondence to Kristen H Griffin; kristen.griffin@allina.com

\section{ABSTRACT}

Objective: To examine patterns of, and decisionmaking processes, informing referrals for inpatient access to integrative medicine (IM) services at a large, acute care hospital.

Design: Retrospective electronic health record review and structured qualitative interviews.

Setting: A 630-bed tertiary care hospital with an IM service available to inpatients.

Participants: IM referrals of all inpatients aged $\geq 18$ years between July 2012 and December 2014 were identified using the hospital's electronic health record.

Fifteen physicians, 15 nurses and 7 administrators were interviewed to better understand roles and perspectives in referring patients for IM services.

Results: In the study hospital, primary sources of referrals for IM services were the orthopaedic and neuroscience/spine service lines. While the largest absolute number of IM referrals was made for patients with lengths of stay of 3 days or fewer, a disproportionate number of total IM referrals was made for patients with long lengths of stay ( $\geq 10$ days), compared with a smaller percentage of patients in the hospital with lengths of stay $\geq 10$ days. Physicians and nurses were more likely to refer patients who displayed strong symptoms (eg, pain and anxiety) and/or did not respond to conventional therapies. IM referrals were predominantly nurse-initiated. A built-in delay in the time from referral initiation to service delivery discouraged referrals of some patients.

Conclusions: Conventional providers refer patients for IM services when these services are available in a tertiary hospital. Referral patterns are influenced by patient characteristics, operational features and provider perspectives. Nurses play a key role in the referral process. Overcoming cultural and knowledge differences between conventional and IM providers is likely to be a continuing challenge to providing IM in inpatient settings.

\section{INTRODUCTION}

In this article, we examine referrals for integrative medicine (IM) services in a large tertiary care hospital, where 'referrals' denotes orders

\section{Strengths and limitations of this study}

- We accessed $2 \frac{1}{2}$ years of electronic health record data to understand the flow of referrals for integrative medicine (IM) therapies in the hospital, a process that has not been reported on previously despite the growing presence of IM services in inpatient settings.

- Qualitative interviews with physicians, nurses and administrators from across the hospital provided insight into how decisions are made surrounding referrals and help to explain or substantiate some of the patterns seen in the electronic health record data.

- This article reports results of a case study from one hospital with a unique and well-established IM programme, and as such, it may have limited generalisability.

- In the course of conducting interviews with physicians and nurses, we learnt that midlevel providers (eg, physician assistants and nurse practitioners) have an important role in placing referrals for IM; however, we did not interview any staff in these roles.

placed within the hospital's electronic health record (EHR) for IM therapies. The integration of complementary medicine modalities (eg, massage, acupuncture and mind-body therapies) with conventional medicine is becoming more common in US healthcare, ${ }^{1-4}$ but occurs infrequently in inpatient settings, where little is known regarding how patients or providers access these therapies. In outpatient settings, IM usage is largely a function of consumer decisions. However, for hospitalised patients, the process by which patients access IM is more complex, with conventional healthcare providers playing an important role in the decision to refer for these services. Without an effective referral process, integration of complementary medicine with conventional medicine cannot occur in inpatient settings. 
Patterns of referrals for IM have been studied previously in health network and primary care settings, but not in a single hospital setting. ${ }^{5}{ }^{6}$ Other studies have examined interprofessional dynamics among conventional and complementary medicine providers in IM clinics and hospitals, ${ }^{78}$ and have described models of IM primary care, with some broad overview of how various referral networks operate. ${ }^{9}$ In this study, we examined referrals for IM within a large, acute care hospital.

\section{METHODS}

\section{Study setting}

Abbott Northwestern Hospital (ANW), a 630-bed teaching and specialty hospital in Minneapolis, Minnesota, has a well-established IM programme available to all inpatients without cost. In this programme, physicians, nurses and other hospital providers order IM as they would any other service in the hospital (eg, a CT scan, physical therapy) using a referral in the EHR system (Epic, Verona, Wisconsin). The creation of the IM programme in 2003 has been described in detail elsewhere. $^{10}$ Initially, the inpatient IM programme was structured around specific clinical areas; however, currently, the IM practitioners can serve patients in any area of the hospital as requested via referrals. IM services, which encompass visits to patients from practitioners offering a range of IM modalities and/or education, generally are available Monday-Friday, from 9:00 to $17: 00$.

During the study period, the IM team comprised 16 credentialed practitioners, including 6 acupuncturists, 8 massage therapists, a holistic nurse and a music therapist (several staffing changes notwithstanding, the IM team currently has a similar composition, with 16 practitioners and 10.6 full-time equivalents). All practitioners are trained in a core curriculum of IM modalities such as relaxation techniques, acupressure and aromatherapy, as well as in approaches to delivering IM therapies in a hospital setting. All acupuncturists on the IM team are licensed and practice under the Minnesota Board of Medical Practice.

The process of placing referrals has evolved since the start of the programme. At the outset in 2003, referrals were made through direct calls from hospital clinicians to the IM team's office. Calls were replaced thereafter by paper orders originating from the EHR, then sent to the IM office and printed out for the team to review and assign. This system subsequently was revised to the process currently in place, in which referrals are placed and viewed using the EHR. Providers on a patient's care team make EHR referrals for IM, and the practitioners triage these referrals, because demand for services often exceeds capacity for service delivery. The triage process happens daily at a morning staff meeting before patient visits begin and is based on a system of flags from the patient's EHR for symptoms such as pain, anxiety, nausea or bowel dysfunction. Notes from referring providers also are considered in decisions about which patients will be seen and by which practitioners. The triage process and decision-making factors affecting it are described in more detail elsewhere from the perspective of IM practitioners at ANW. ${ }^{11}$

There are two major categories of referrals for IM: acupuncture and general IM consults; the latter can encompass any of the IM services available. Acupuncture orders also can result in an acupuncturist delivering a service other than acupuncture (eg, acupressure, mind-body therapy). Acupuncture referrals require authorisation in the EHR by a physician or midlevel provider, while general IM referrals can be placed by nurses and other providers. General IM referrals can be fulfilled by acupuncturists and other IM practitioners, but only acupuncturists can respond to acupuncture referrals.

\section{Data}

In describing the flow of inpatient referrals, we tracked all inpatients aged 18 years or older at ANW, who were admitted between 16 July 2012 and 15 December 2014. We excluded patients who were seen as outpatients, in the emergency room, or who were in the hospital solely for observation. EHR data were obtained on all eligible inpatients. All patients whose EHR data were obtained gave written permission upon or prior to admission to the hospital to use their records for general research purposes. As such, the retrospective data collection portion of this study was approved by the Quorum Institutional Review Board with a waiver of informed consent. We amended the study protocol (available as online supplementary file) to include qualitative interviews with providers.

We collected interview data to understand the influence on referrals of physicians', nurses' and administrators' own attitudes and beliefs towards integrative care and their professional experience ordering IM for their patients at ANW. We interviewed physicians, nurses and administrators across five clinical service lines at ANW: oncology, maternity care ('Mother Baby'), cardiovascular, neuroscience and spine, orthopaedics (administrators and physicians only) and the hospitalist service (administrators and physicians only). Physicians and nurses were divided, based on referral records, into 'high-referring' and 'low-referring' designations before recruitment began, in order to ensure that providers in the study represented frequent and occasional referrers for IM services.

Our goal was to recruit two high-referring and two low-referring physicians and nurses in each service line, resulting in a total of 24 physicians and 16 nurses. There were no nurses associated with the hospitalist group. Orthopaedic nurses were not recruited for the study because of the presence of standing orders on the joint replacement area of the orthopaedic unit, a topic discussed in the Results section of this article. The lists of 
high-referring and low-referring physicians and highreferring and low-referring nurses were placed in random order before recruitment began. Additionally, we planned to recruit physician administrators for each of the six service lines, in order to obtain their insights into how IM is perceived, used and supported in each service line. All administrators were practicing currently as physicians in their service lines, in addition to their administrative roles. Prospective participants received emailed or mailed invitations from the study principal investigator (JAD) and follow-up contacts by the study coordinator (KHG) if they did not respond to the initial invitation.

Structured interview protocols (available as online supplementary file) were developed by the study team and approved by the institutional review board. An interpretivist paradigm was used in creating the interview guides and subsequently in analysing the data. All protocols addressed professional background and personal experience with IM. Administrators were asked to assess the knowledge and support of IM services by providers in their service lines, as well as their own personal and professional perspectives on IM. Physicians and nurses were asked about their use of the IM referral system and interactions with patients and patients' family members regarding IM services.

Interviews were audio-recorded using a handheld digital recorder and then were transcribed by an independent transcriptionist. Transcripts were organised and coded using Atlas.ti V.7.5.4 software. The analysis process was ongoing, as transcripts became available. The interview protocol questions were used to establish a basic coding structure, to which inductive analysis ${ }^{12}$ principles then were applied. The inductive analysis process involves open coding to develop codes, categories, patterns and themes. These elements then are refined using deductive processes to form analytical hypotheses about the data. Different code catalogues were created for each participant group (ie, physicians, nurses and administrators).

Although random selection of physician and nurse participants was intended to occur until two interviews were completed from the high-referring and the lowreferring groups for each clinical service line, data saturation (the point at which no new themes emerged during analysis) was reached in all groups before initial recruitment numbers were achieved. Methods are described further in online supplementary file. In total, 37 hospital staff and affiliates were recruited (table 1 and figure 1).

\section{RESULTS}

\section{Referrals}

During the study period, there were $\sim 14000$ referrals for IM services at ANW hospital, out of 84 000 unique admissions (table 2). A higher percentage of middle-aged and female patients were referred for IM services. Referrals were tracked across several different service lines, and the greatest number of referrals came from the orthopaedics and neuroscience/spine service lines (table 3). In the case of orthopaedics, this reflects the presence of standing orders for IM referrals in the hospital's joint replacement programme, as discussed in the interview findings. A quality improvement project with spine patients that took place during the study period may partially account for the high number of referrals in that service line. Patients with lengths of stay of three or fewer days constituted the bulk of first referrals (defined as the first referral placed for IM during a hospital admission), but a relatively small portion of these patients were referred. In contrast, a larger proportion of long-stay patients were referred for IM services, while the absolute number of these patient referrals was smaller (table 2). The median time from first referral for any IM therapy until contact with an IM practitioner (ie, fulfilment) was $\sim 23$ hours, ranging from just under 22 hours for neuroscience/spine referrals to over 48 hours for rehabilitation referrals, with response times for most service lines falling between 22 and 25 hours (table 3). Longer median patient stays generally were associated with longer referral to response times across service lines.

\section{Interview findings}

We organised themes that emerged from the interviews into three general categories: criteria used by clinicians to make referrals; factors influencing the referral process; and concerns and challenges related to having an IM programme available in the hospital.

\section{Criteria for IM referrals}

In response to a broadly stated question about what circumstances or characteristics would lead someone to refer a patient to IM, respondents mentioned the

Table 1 Occupations and clinical service lines of qualitative interview participants

\section{Clinical service line}

\begin{tabular}{lllllllr}
$\begin{array}{l}\text { Provider } \\
\text { type }\end{array}$ & Oncology & Cardiology & $\begin{array}{l}\text { Mother } \\
\text { Baby }\end{array}$ & $\begin{array}{l}\text { Neuroscience } \\
\text { and spine }\end{array}$ & Orthopaedics & $\begin{array}{l}\text { Hospitalist } \\
\text { service }\end{array}$ & \multicolumn{1}{c}{ Total } \\
\hline Administrator & 1 & 1 & 1 & 2 & 1 & 1 & 7 \\
Physician & 4 & 2 & 3 & 2 & 2 & 2 & 15 \\
Nurse & 4 & 3 & 4 & 4 & NA & NA & 15 \\
\hline
\end{tabular}


Figure 1 Recruitment of interview participants.
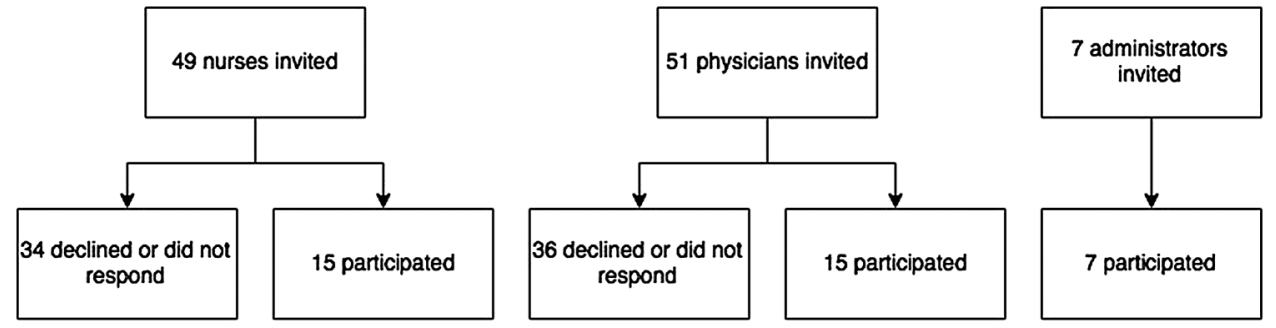

Table 2 Demographics of inpatients at ANW 16 July 2012-15 December 2014

\begin{tabular}{|c|c|c|c|}
\hline & $\begin{array}{l}\text { Total } \\
(\mathrm{N}=83677)\end{array}$ & $\begin{array}{l}\text { No IM referral } \\
(\mathrm{N}=69686)\end{array}$ & 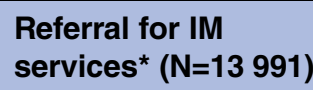 \\
\hline \multicolumn{4}{|l|}{ Age } \\
\hline 40 to 59 & $21481(25.7 \%)$ & $17053(24.5 \%)$ & $4428(31.6 \%)$ \\
\hline 60 to 79 & $28077(33.6 \%)$ & $22371(32.1 \%)$ & $5706(40.8 \%)$ \\
\hline$\geq 80$ & $13220(15.8 \%)$ & $11813(17.0 \%)$ & $1407(10.1 \%)$ \\
\hline Male & $33683(40.3 \%)$ & $28920(41.5 \%)$ & $4763(34.0 \%)$ \\
\hline \multicolumn{4}{|l|}{ Primary race } \\
\hline American Indian or Alaska Native & $1567(1.9 \%)$ & $1349(1.9 \%)$ & $218(1.6 \%)$ \\
\hline Asian & $1619(1.9 \%)$ & $1452(2.1 \%)$ & $167(1.2 \%)$ \\
\hline Black or African-American & 7991 (9.5\%) & $7143(10.3 \%)$ & $848(6.1 \%)$ \\
\hline Native Hawaiian or other Pacific Islander & $151(0.2 \%)$ & $134(0.2 \%)$ & $17(0.1 \%)$ \\
\hline Patient declined & $790(0.9 \%)$ & $687(1.0 \%)$ & $103(0.7 \%)$ \\
\hline Caucasian, not Hispanic/not Latino & $81226(97.1 \%)$ & $67532(96.9 \%)$ & $13694(97.9 \%)$ \\
\hline Hispanic or Latino & $1661(2.0 \%)$ & $1467(2.1 \%)$ & $194(1.4 \%)$ \\
\hline \multicolumn{4}{|l|}{ Marital status } \\
\hline Life partner, married, significant other & $45604(54.5 \%)$ & $37686(54.1 \%)$ & $7918(56.6 \%)$ \\
\hline Separated, divorced & $7587(9.1 \%)$ & $6062(8.7 \%)$ & $1525(10.9 \%)$ \\
\hline Widowed & $9562(11.4 \%)$ & $8230(11.8 \%)$ & $1332(9.5 \%)$ \\
\hline Single & $20812(24.9 \%)$ & $17608(25.3 \%)$ & $3204(22.9 \%)$ \\
\hline Unknown, other & $112(0.1 \%)$ & $100(0.1 \%)$ & $12(0.1 \%)$ \\
\hline \multicolumn{4}{|l|}{ Length of stay } \\
\hline 1 to 3 & $50782(60.7 \%)$ & $44981(64.5 \%)$ & $5801(41.5 \%)$ \\
\hline 4 to 6 & $18794(22.5 \%)$ & $15236(21.9 \%)$ & $3558(25.4 \%)$ \\
\hline Neuroscience and spine & $12249(14.6 \%)$ & $9624(13.8 \%)$ & $2625(18.8 \%)$ \\
\hline Oncology & $5813(6.9 \%)$ & $4533(6.5 \%)$ & $1280(9.1 \%)$ \\
\hline Orthopaedic & $6151(7.4 \%)$ & 2839 (4.1\%) & $3312(23.7 \%)$ \\
\hline Rehabilitation & $1387(1.7 \%)$ & $705(1.0 \%)$ & $682(4.9 \%)$ \\
\hline
\end{tabular}

following four criteria: patients' actual or expected length of stay, symptoms, using IM as a 'last resort' and patients specifically requesting IM.

Length of stay and chronic conditions: Nurses, physicians and administrators frequently mentioned that patients who were in the hospital longer (or were expected to be in the hospital longer) than average were common candidates for receiving an IM referral. Typically, these were individuals with chronic conditions. One physician suggested that 'our chronic, long-term players' would be a 


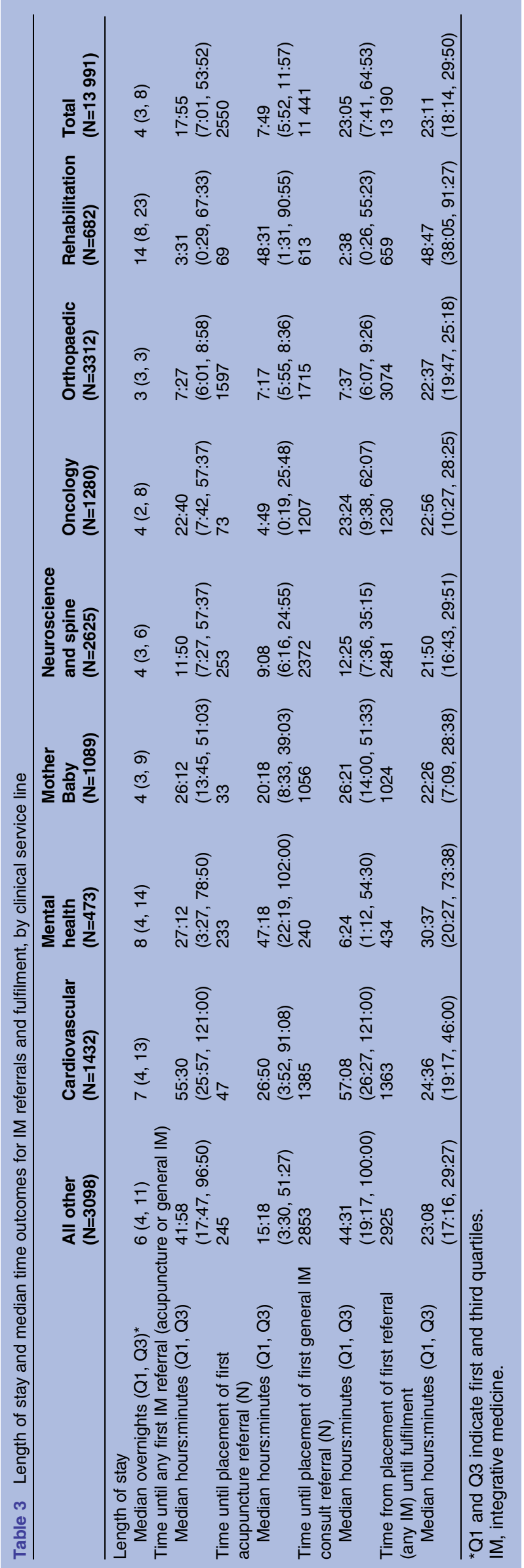

promising group to receive more IM in the hospital than they do at present. An administrator and several physicians described IM as not being relevant for young, otherwise healthy surgical patients who recover quickly from surgery and have short lengths of stay. Conversely, this administrator said, 'there are patients with chronic conditions who've had chronic pain for a long time, and I think those are the patients that I would look to helping [with IM], and where you could reduce pain medication'. Similarly, Mother Baby nurses and physicians reinforced the idea that longer term-typically antenatal-patients in their service line were more commonly referred for IM, versus labour and delivery patients whose hospital stays were too short for IM to be helpful or feasible.

I would be much more inclined to use it for the people who are chronically hospitalized. Or, if somebody's had a very complicated course, and we know-either we're pretty sure they're going to be here much longer than a routine person, or it just turns out they have been here longer and that's part of the problem, you know, they're having trouble dealing with that discouragement and putting up with that. Yeah, but it's almost always chronic, chronic people that I would call for. (Physician)

A large proportion of longer stay patients in the Mother Baby service line was confirmed by the referral data, where among Mother Baby patients with lengths of stay longer than 10 days, $82 \%$ were referred for IM. In contrast, among Mother Baby patients with lengths of stay from 1 to 3 days, only $4 \%$ were referred for IM. Providers who were hesitant to refer shorter length of stay patients expressed concern that services are not typically available until the day after the referral is made, a topic discussed further below (under the Factors influencing the referral process section).

Importance of patient symptoms: IM referrals were cited by all physicians, nurses and administrators as being driven by patient symptoms, primarily pain, anxiety and stress or difficulty coping. Nausea was mentioned as well, particularly in the case of oncology patients. Often, providers viewed IM therapies as a method to reduce the use of medications, especially those that may have adverse side effects. A patient's health condition or reason for hospitalisation was not the principal driver of the decision to make a referral; rather, the common element was almost always related to symptoms.

A lot of times...the people who have the most expressed amount of pain [are referred]. And especially the people who are having a difficult time with trying to cope with the hospitalization and the difficulties that come with it. (Nurse)

Use as last resort: Frequently, physicians, nurses and administrators saw IM services as an option to use in caring for patients when the providers had exhausted all other strategies. There were references to 'difficult 
patients' who did not seem to respond to any other treatment or whose anxiety was very persistent. Participants felt that it 'cannot hurt' to try IM, and at best it might provide some sense of relief, comfort or improvement for challenging patients.

It's for people that don't have heart disease but are desperate for some kind of way to feel better. And so, I've ruled everything out that's deadly, and then it's like, "oh, there's not really something else, I can't really do anything else, try this." (Physician)

I just see that is something else they will benefit from. I'm like, "Have you tried this? OK, we have this and...you can also benefit from that," especially if we've tried everything else and they seem not to be comfortable. (Nurse)

Patients with complex sets of circumstances and conditions were mentioned frequently as those whom providers might refer. For example, one physician described working with complex patients who are being treated with multiple medications, and the hope that nonpharmacologic IM treatment might provide additional relief without drugs:

I deal with very sick patients, with essentially end-stage heart failure. A frequent accompaniment of the comorbidities is anxiety and pain. And also they tend to be elderly, and they've had arthritic conditions. And these patients are usually already heavily medicated on polypharmacy. So any other therapeutic interventions I can make which don't involve pills, and which may actually be more effective, I would rather go down that road. (Physician)

Several respondents from each of the three provider groups mentioned the value of IM as an alternative to medications, whether because a patient was already on the maximum amount of medication he or she could be given, or because the patient expressed an interest in trying a non-pharmacological approach to manage his or her symptoms.

Patient request: Some physicians and nurses mentioned ordering IM when patients requested it. This view was most frequently mentioned in response to an interview question about whether or not patients ever initiated a request for services, although a few participants raised it without being prompted. According to participants, occasionally patients and/or family members do directly request IM services. Typically, these patients have experienced IM services previously (either at ANW or elsewhere in outpatient settings), or friends or family members have recommended the services.

Some of them...they ask for it. They start asking for, "Oh, can I get integrative medicine to come see me?" Or, "I need acupuncture." Or they want massage. And most of them will ask for it already, then I put the referral in...I think the ones that ask for it...they've been to alternative medicine or had integrative medicine before. (Nurse)

\section{Factors influencing the referral process}

Beyond the criteria used to make decisions about who is referred for or receives services, a number of factors influence how and why providers make referrals, for example, conditions in the workflow that are perceived as facilitating or limiting engagement with or usefulness of IM. Three primary factors emerged in the interviews: the presence of standing orders on a unit (where all or nearly all patients receive an IM referral), the role of nurses and/or midlevel practitioners in driving most referrals (midlevel practitioners, eg, nurse practitioners and physician assistants, were not interviewed in this study) and the overall operational characteristics of the referral process.

Standing orders: On several inpatient units in the hospital, standing orders or quality improvement projects existed for specific medical conditions or procedures (eg, hip/knee replacements and spinal fusion). One oncologist also described having IM referrals ordered for all her patients. This approach increased the number of referrals for IM but then left the decision to accept IM services with the patient (who, according to the physician, typically did not know about the referral) when the IM practitioner arrived to provide services. Physician attitudes on standing orders ranged from enthusiastically supportive to somewhat detached (a version of the 'it can't hurt' approach). A repeated idea related to standing orders is that patients always have the option to decline IM services.

[W]e found it was so beneficial for the ones that were electing to do it within the first year that we felt we should standardize it for everybody, and then the patients still have the option to opt out and surgeons still have the option to opt out, but most of the surgeons don't. (Administrator)

So they're on our order sets as augments for breast cancer and our colon cancers. And so we, I order them on everybody. But whether or not the patients want to do it, how much they do, I don't really know...So the consult gets ordered, and then they will come and evaluate the patient. Then the patient ultimately gets to decide what they want or don't want. (Physician)

Nursing-driven service: Physicians and administrators consistently described the IM referral process as being driven primarily by nurses (except in the case of standing orders). Nurses had the authority to refer for a general IM consult, although a physician was required to authorise an acupuncture order. In addition, the nursedriven nature of the IM referral process was attributed by nurses and physicians to the fact that nurses spend the most time interacting with patients and thus have a better sense of whether patients may be receptive to or helped by IM. Many physicians also emphasised the central role of physician assistants and nurse practitioners in determining patients who should receive IM and in placing IM referrals, due to the greater amount 
of time these midlevel providers spent interacting with patients.

When asked whether there were ever differences of opinion between nurses and physicians on whether a patient should receive IM, nurses consistently said that physicians were supportive of the nurses' judgment regarding whether IM could benefit the patient. The situations identified where a physician might not support an IM referral related to patients with conditions (eg, bleeding disorders and sutures) that might preclude the use of a modality like acupuncture or massage, although these exceptions were mentioned infrequently by interviewees.

Well, I think, I mean the nurses are better about thinking about this, and I think having them able. I don't know. I think having them ask for integrative medicine consults has probably accomplished more than depending on the doctors to think about it themselves...We're just sort of trying to get through the day, and they're there with the patient all day, and so they're more likely to think about it. (Physician)

The nurses, the RNs, are usually the ones who identify patients who may benefit and they make a suggestion. I could tell you, neither myself or, for that matter, probably any physician within my group would say, would turn down an $\mathrm{RN}$ request for integrative medicine... So it's usually an RN-driven, an RN-driven consult for the most, a lot of times. (Administrator)

A physician who stated that she actually was more likely than her nurses to place an IM referral for her patients emphasised that she and the nurses generally agreed about whether a patient should receive IM and that she would support placing a referral on a nurse's suggestion.

Issues regarding how the referral process functioned: Most nurses and physicians remarked that the referral process generally worked well for them, with some mentioning that it was quick and easy to use, and others commenting positively on their interactions with the IM practitioners who regularly visited their units. Caveats such as wishing for IM weekend services ('pain doesn't stop on the weekends', one nurse said) or more IM practitioner availability were generally qualified by comments that the system works well given its size and scope.

The primary factor found to negatively influence referrals, from the perspective of all groups interviewed, was the timing of IM service delivery relative to when a referral was made. Typically, referrals placed were not seen the same day, reducing the usefulness of services in acute episodes of care. Referring providers expected a lag time of a day or more between the referral and service delivery, which may be one reason that referrals were placed for a relatively high percentage of patients who had longer lengths of stay. One of the physician administrators said, 'I think there's a lot of people that I would otherwise use it for if it was more readily available quickly'. Other providers felt the delay was not a problem because of the non-critical nature of using IM and due to the fact that chronic, longer term patients were generally-in their experiences-the best fits for receiving IM anyway.

IM services are only offered Monday-Friday during the day shift, contributing to the gap between referral and service delivery as well as occasionally prompting providers not to place referrals on Fridays (due to the lack of IM services on weekends). Several participants discussed concerns about shorter stay patients potentially wanting to stay in the hospital until they had received their IM session. This issue of patient expectation or desire to receive the service occasionally influenced provider decisions regarding referring for IM.

I think sometimes [patients] wish it was more often. Or like, you know, when you talk about the referral, sometimes they don't get it till the next day or even the following day. So I think sometimes they would probably want it, like, more quickly, right after it's put in...If I have patients going home the next day, then I won't put it in. Because I know that it would probably be useless. (Nurse)

Generally, however, referring providers found the service to be useful despite its limitations related to timing.

\section{Clinician concerns and challenges related to the presence of IM in the hospital}

Although clinicians generally felt that the IM service was beneficial for their patients, they did raise concerns, and made suggestions, related to the presence of the IM service in general. These included a desire for more information about IM and the recognition of inherent differences between the pace and philosophy of complementary healing approaches and conventional western medicine.

Desire for better education and information about IM: A commonly raised concern, on the part of physicians more than nurses, was a desire for more information and education about IM offerings and evidence of their effectiveness. The physicians we interviewed did not recall receiving formal training or education on the hospital's IM services or the referral process. For some participants, their concerns regarded a lack of familiarity with the IM modalities actually available to patients. This was true even among physicians who had personal experience using IM modalities in outpatient settings. Some felt that they could better discuss IM as a possibility with patients if they were more familiar with the 'menu' of services at the hospital. Others wanted more information regarding which modalities might be most useful for specific patient symptoms. One physician, in discussing a wish to see more collaboration between IM providers and his patients' care teams, said, 'maybe I'm sending inappropriate referrals...Is this the right patient 
to refer for this consult, and is this the right thing to ask for?' This comment was consistent with a sentiment expressed by other physicians that they were not always confident in how best to use the IM service and that they would appreciate more clarity from the IM team in this regard.

Nurses, on the other hand, generally had more familiarity with the IM programme offerings. While neither nurses nor physicians said that they had received formal training from the IM programme, many nurses had completed education modules at some point in their careers on nurse-delivered aromatherapy or other nursedelivered services. They were also more likely to see and interact with IM practitioners. Thus, even if their training had been informal, they were more familiar with the IM programme, and they expressed less interest than physicians in receiving additional information on the programme. This finding fits with the theme, described previously, of a high degree of nurse involvement with the referral process.

Another concern related to information/education focused on the evidence base for IM. Physicians and administrators, in particular, expressed a desire for more information about the efficacy and safety of IM modalities, from IM research conducted at ANW and in the medical literature at-large.

Well, I think it's a good thing, but again, I don't know efficacious it is. Meaning that I think there's literature to support it...and I think that it draws some patients. But again, I don't know how we're evaluating it. Is there something that should be more cookbook, that patients that have bowel surgery should have lavender post-op to help with their nausea? It doesn't seem like it's very wellprescribed. (Physician)

Balancing two different approaches to medicine: Clinicians often noted that supporting and engaging with IM in the hospital can be simultaneously challenging and valuable, because it represents the meeting of two different paradigms: conventional/western medicine and complementary and alternative medicine. Some clinicians pointed to this as a motivating factor for placing a referral; in particular, more experienced nurses commented on how they previously had the time to provide some of the comfort now given by IM providers, but that their pace of work no longer allowed for that level of care. Hence, they viewed IM as filling an important role in the rushed modern medicine model. One physician described this role as 'develop[ing] a little stillness and peace in the hospital'. Several physicians perceived the IM service to be underused.

A physician administrator commented on the two different paces of IM and conventional medicine:

[W] e get very busy, so, we rush through and we, we're focusing on sort of absolute vital parameters regarding the patient. We're focusing on getting the patient out of the hospital quickly, and I think that a lot of the increased pressure to move patients out quickly is perhaps taking away a little bit of the, you know, integrative medicine is a, I think it's a really good system, and I think for chronic pain patients, it can be extremely helpful. But we have to fit it in, a kind of a slower-paced concept, into this fast-paced, get your physical therapy, get your x-ray, get walking, and get out of here. And patients need a little bit more than that. Sometimes there are times when patients need to be a little quieter, if their bodies need time to heal...And so, and I think this, this pressure we're feeling to move patients out of the hospital quickly is detracting a little bit from the opportunities. And I think that it would be worthwhile for us to explore the use of integrative medicine, not only while they're in the hospital, but to teach them techniques that they can continue after they leave. (Administrator)

Connecting inpatient and outpatient settings: Lastly, several physicians were concerned that, while IM is especially suitable for long-term treatment of chronic issues and for recovery after discharge, currently there is not an obvious mechanism for linking patients to continued IM services once they are discharged. This applied to physicians who used the service for their patients regularly and recognised its limits as well as to those who referred infrequently but recognised the potential of IM to help patients under more ideal circumstances.

And so it's about how you describe it in a way that gets insurance to cover it and things like that. That's more the obstacle, will they cover this or not. While you're here in the hospital, it's fine. But my patients, I see longitudinally over years and years and years...And so, after the acute phase, there's this other phase where it [IM service] is particularly necessary and that's where it becomes a resistance, is that you can offer something in the hospital, but then, because of financial issues, the patients can't keep it up, so if that strategy is your strategy, and then you can't use it, it becomes a little hard to, to offer it in one place and then not be able to sustain it. (Physician) (emphasis speaker's)

\section{DISCUSSION}

The present study provides a unique window into how patients access IM services at one US tertiary care hospital. That the provision of integrative therapies is distinct in nature from other hospital care at ANW, and that it is optional, was cited as a motivating factor for why providers might place a referral: to improve the patient's inpatient experience in ways that might not otherwise be possible using conventional medical approaches. We found that the IM referral process is very rooted in nursing, suggesting the importance of ongoing interaction between IM providers and hospital nurses for the success of inpatient IM programmes. Since a nurse was the key developer of the IM service, ${ }^{10}$ the link to nursing is understandable. The presence of nurses on the IM team may be a factor in the acceptance by nurses of the service. In a separate set of interviews with the IM practitioners at ANW, those who had 
nursing backgrounds described their experiences of feeling accepted by nurses on the floor, due to being well-versed in the language, culture and workflow of conventional medicine and nursing practice. ${ }^{11}$

Neither physicians nor nurses described training on the referral process that was systematic or driven by the IM programme. Some respondents were better informed than others, but knowledge was uneven among staff in all service lines, depending on interest level, work hours, time in the position and team dynamics. Given the concern articulated by physicians about a need for more thorough education regarding the merits of and best uses for IM, information on research findings related to IM should be made available to interested physicians, as well as information on programme offerings and recommendations regarding which patients may benefit most from receiving IM.

We found that projected or actual length of stay can have a bearing on whether a patient is referred for IM; however, we must interpret this theme cautiously. While the tendency to refer longer stay patients may be related to an operational delay in service delivery that would make short-stay patients less likely to be seen, it is also possible that chronically ill patients with longer stays may be referred commonly for IM simply because providers work with these patients longer and have more time to consider what combination of conventional and IM approaches may help them.

As in all case studies, an inherent limitation of this study is that our findings may not be generalisable to all inpatient settings where similar programmes now exist or are being considered. However, the structure and operations of ANW are fairly typical of a large, tertiary care hospital in the USA. Another potential limitation is that the 30 physicians and nurses who agreed to be interviewed (30\% of those invited) may have been different than those who declined or did not respond, despite the use of randomised lists of prospective participants in recruitment. The designation of 'high-'referring and 'low-'referring providers, which was intended to capture a representative range of engagement with the IM services, was not as meaningful as expected. Some highreferring physicians, according to clinical records, were in units with standing orders for IM; therefore, they did not engage in regular decision-making regarding IM referrals. Alternately, some low-referring providers did not place many referrals directly, but regularly supported staff who did. In general, high-referring providers had more regular contact and engagement with IM services than low-referring providers, but uncovering the exceptions to this pattern revealed a nuance in the referral system, whereby a provider's referral frequency was not necessarily indicative of his or her level of support for or interaction with the IM referral process.

Finally, several nurses and physicians mentioned the important role of midlevel providers such as physician assistants and nurse practitioners in referring for IM, but we did not include any of these providers in our recruitment for interviews. However, the referral role of these midlevel providers was itself a useful finding of the study that could inform future research into the flow of referrals in inpatient settings. In the USA, midlevel providers play an increasingly important role in hospitals, as use of these providers is incentivised and supported at policy and administrative levels. ${ }^{13}$ Further research on referrals for IM services within hospitals should include midlevel providers in the study design.

In addition to study limitations, the current research highlighted operational elements of the IM programme at ANW that merit review. Primarily, the delay between referral and service delivery emerged as a common reason why providers might not consider using the service with some patients. Although providers generally accepted this delay as part of how the programme functions, same-day delivery of IM services potentially could allow the system to reach more patients who currently do not have the opportunity to receive IM. Since the conclusion of the study period, several IM practitioners at ANW have been 'embedded' on the Mother Baby and spine units, thus reducing the time from referral to fulfilment, so such a change has been possible in this setting. The tendency for the demand for IM services to exceed supply likely contributes to the delay in service delivery, and the high demand may be related to the service being offered at no cost to patients. We previously addressed this challenge in an analysis of IM practitioner views of providing inpatient services. ${ }^{11}$ However, we did not gather from our interviews that concerns about the service being free deterred providers from referring for the service in general.

Another operational feature potentially unique to ANW's IM service is the nature of how standing orders for IM services are implemented. At present, all instances of standing orders for IM are very specific (eg, the order in joint replacement programme is for group acupuncture, the order in the spine service line was related to a temporary and now-completed quality improvement project). It may be of interest in future analyses to examine the influence of standing orders more closely. As IM programmes become more prevalent in US hospitals, it will be important to draw on the successes and challenges of existing models such as the ANW IM service. Our study addresses several gaps in the literature with regard to the provision of IM in US hospitals, as IM referral processes within an inpatient setting have not been studied previously. Although IM is increasingly being provided to US inpatients in areas such as oncology ${ }^{14} 15$ and paediatrics, ${ }^{16}{ }^{17}$ hospitals with well-established IM offerings for inpatients are more prevalent internationally (eg, in Israel, ${ }^{18}{ }^{19}$ Germany $^{20}{ }^{21}$ and $\mathrm{China}^{22}$ ). However, operational processes and cultural contexts surrounding acceptance of IM are substantially different internationally in comparison with the USA, where IM offerings are less widespread and assimilated. ${ }^{4}$ Furthermore, international studies have examined feasibility and outcomes of inpatient IM, but 
inpatient IM referral patterns have not been described. IM referral patterns have been explored within a US health network ${ }^{5}$ and in an Australian primary care setting, ${ }^{6}$ but not, to the best of our knowledge, within a single inpatient facility offering IM as ANW does.

The culture and challenges of providing inpatient IM have been described from the perspectives of the IM practitioners who provide services; ${ }^{11}{ }^{23}$ however, it is also valuable to consider the views and decisions of the conventional medical providers who provide a crucial link to patients for receiving integrative therapies. Research on healthcare providers' perspectives on IM has been used primarily to examine provider awareness of IM and opinions on its general usefulness or perceived legitimacy in an ambulatory setting. ${ }^{24-26}$ Qualitative interviews by Grant and Bensoussan, ${ }^{27}$ which included a respondent from the ANW IM programme, focused on the 'process of care' in integrative healthcare programmes at a broad level, addressing topics such as organisational structure and the use of practice guidelines; however, all but one other of the nine programmes described in that study were outpatient settings. One interview-based study of physician and IM practitioner views on a short term, integrative collaboration for treating hospitalised multiple sclerosis patients reflected a much more specific and limited setting than our hospital-wide study. It also revealed themes related to the importance and challenges of collaboration and organisational support in integrating conventional and alternative therapeutic approaches. $^{28}$

To date, studies about IM that have included nurse perspectives have focused primarily on assessing the knowledge and attitudes of nurses towards complementary therapies. ${ }^{25}$ 29-33 Generally, attitudes are positive, although reported knowledge about complementary therapies is highly variable from study to study. A qualitative study that included nurses reported interviewee attitudes towards integration of conventional and complementary medical approaches and found nurses to be supportive and interested. ${ }^{34}$ One study conducted among oncology patients in inpatient and outpatient settings found that patients perceived nurses to be important figures in decision-making processes around IM use, ${ }^{35}$ but nurses were not interviewed.

There is evidence in the USA of poor to moderate physician-patient communication about outside complementary medicine use ${ }^{36-41}$ or resistance by physicians to their patients using complementary or alternative therapies. ${ }^{42}$ Generally, however, this resistance or disengagement has been reported with regard to patient use of these therapies outside the context of conventional medical care, in other words, in situations where use of therapies is driven by patients as healthcare consumers. Since IM programmes embedded in hospitals are relatively new, evidence of provider attitudes about complementary therapies in the inpatient setting has not been addressed in the literature prior to this study. Furthermore, resistance by conventional providers to integrative therapies for patients may be diminishing. Several surveys have found supportive attitudes by physicians for the use of complementary and integrative therapies. $^{24} 4445$ A recent qualitative study with physicians, nurses and administrators at a large veterans' medical centre reported that respondents recognised the role of complementary medicine in making care more patientcentred. ${ }^{34}$ And physicians at an academic medical centre where complementary therapies were offered showed a marked increase in their willingness to refer patients to those therapies over the course of an 8 -year period. ${ }^{46}$ We generally found acceptance among providers interviewed for this study; even those who referred for IM infrequently tended to feel that the service was beneficial with regard to patient satisfaction and expressed the view that it 'cannot hurt'.

In addition to seeking perspectives from midlevel providers, as suggested above, future research should address patient perspectives, as patients (and/or their family members) also play a role in the referral process. Beyond qualitative research, some investigation into how a system might respond to the concerns or suggestions articulated here by nurses, physicians and administrators may be warranted. For example, a number of physicians expressed a desire to see more of a transitional process established for patients between IM services received in the hospital and outpatient services after discharge, implying a recognition of the potential long-term value of integrative care. As other hospital IM programmes develop, questions should continue to be asked about referral processes, use of resources and cultural integration in order to design better programmes and streamline existing ones. Same-day referrals or approaches based around clinical service lines rather than hospitalwide programmes would be worth consideration.

\section{CONCLUSIONS}

Conventional providers refer patients for IM services when these services are available in a tertiary hospital. Referrals are driven primarily by patient symptoms such as pain and anxiety, and patients with longer hospital stays are viewed as appropriate and feasible referral candidates. Nurses are a major source of IM referrals and have a great deal of support from physicians in their decision-making processes surrounding IM. Overcoming cultural and knowledge differences between providers of conventional versus complementary medicine is likely to be a continuing challenge to the provision of IM in inpatient settings.

Acknowledgements The authors thank Jill Johnson and Michael Finch for their feedback on an earlier version of this manuscript. The authors also thank the participating administrators, physicians and nurses at Abbott Northwestern Hospital for their time.

Contributors KHG collected, coded and analysed qualitative data; interpreted findings; and drafted the manuscript. KCN coded and analysed qualitative data, interpreted findings and contributed to drafting. RLR managed and analysed electronic health record data, interpreted findings and contributed to drafting. JBC conceptualised the study, collected data and contributed to 
drafting. JAD conceptualised the study and contributed to drafting. All authors gave final approval of the current version.

Funding This work was partially supported by the National Center for Complementary and Integrative Health of the National Institutes of Health (grant number R01 AT006518 to JAD).

Disclaimer The content is solely the responsibility of the authors and does not necessarily represent the official views of the National Institutes of Health.

Competing interests None declared.

Ethics approval Quorum Institutional Review Board.

Provenance and peer review Not commissioned; externally peer reviewed.

Open Access This is an Open Access article distributed in accordance with the Creative Commons Attribution Non Commercial (CC BY-NC 4.0) license, which permits others to distribute, remix, adapt, build upon this work noncommercially, and license their derivative works on different terms, provided the original work is properly cited and the use is non-commercial. See: http:// creativecommons.org/licenses/by-nc/4.0/

\section{REFERENCES}

1. Barnes P, Bloom B, Nahin R. Complementary and alternative medicine use among adults and children: United States, 2007. Hyattsville (MD): National Center for Health Statistics, 2008.

2. Frass M, Strassl RP, Friehs $\mathrm{H}$, et al. Use and acceptance of complementary and alternative medicine among the general population and medical personnel: a systematic review. Ochsner $J$ 2012;12:45-56.

3. Kanodia AK, Legedza AT, Davis RB, et al. Perceived benefit of complementary and alternative medicine (CAM) for back pain: a national survey. J Am Board Fam Med 2010;23:354-62.

4. Halm MA, Katseres J. CE: integrative care: the evolving landscape in American hospitals. Am J Nurs 2015;115:22-9.

5. Coulter ID, Singh BB, Riley D, et al. Interprofessional referral patterns in an integrated medical system. J Manipulative Physiol Ther 2005;28:170-4.

6. Gray B, Orrock P. Investigation into factors influencing roles, relationships, and referrals in integrative medicine. $J$ Altern Complement Med 2014;20:342-6.

7. Hollenberg D. Uncharted ground: patterns of professional interaction among complementary/alternative and biomedical practitioners in integrative health care settings. Soc Sci Med 2006;62:731-44.

8. Gaboury I, Lapierre LM, Boon H, et al. Interprofessional collaboration within integrative healthcare clinics through the lens of the relationship-centered care model. $J$ Interprof Care 2011;25:124-30.

9. Templeman K, Robinson A. Integrative medicine models in contemporary primary health care. Complement Ther Med 2011;19:84-92

10. Knutson L, Johnson PJ, Sidebottom A, et al. Development of a hospital-based integrative healthcare program. J Nurs Adm 2013;43:101-7

11. Nate KC, Griffin $\mathrm{KH}$, Christianson JB, et al. Practitioner perspectives on delivering integrative medicine in a large, acute care hospital. Evid Based Complement Alternat Med 2015;2015:394040.

12. Patton M. Qualitative research and evaluation methods. 3rd edn Thousand Oaks (CA): Sage, 2002.

13. Manchikanti L, Caraway DL, Parr AT, et al. Patient Protection and Affordable Care Act of 2010: reforming the health care reform for the new decade. Pain Physician 2011;14:E35-67.

14. Kligler B, Chesney M. Academic health centers and the growth of integrative medicine. J Natl Cancer Inst Monogr 2014;2014:292-3.

15. Seely DM, Weeks LC, Young S. A systematic review of integrative oncology programs. Curr Oncol 2012;19:e436-61.

16. Cotton S, Luberto CM, Bogenschutz LH, et al. Integrative care therapies and pain in hospitalized children and adolescents: a retrospective database review. J Altern Complement Med 2014;20:98-102.

17. Misra SM, Guffey D, Tran X, et al. Survey of complementary and alternative medicine (CAM) services in freestanding US children's hospitals. Clin Pediatr (Phila) 2016. [Epub ahead of print $29 \mathrm{Apr}$ 2016]. doi:10.1177/0009922816645513

18. Schiff $\mathrm{E}$, Attias $\mathrm{S}$, Hen $\mathrm{H}$, et al. Integrating a complementary medicine service within a general surgery department: from contemplation to practice. J Altern Complement Med 2012;18:300-5.
19. Attias S, Keinan Boker L, Arnon Z, et al. Effectiveness of integrating individualized and generic complementary medicine treatments with standard care versus standard care alone for reducing preoperative anxiety. J Clin Anesth 2016;29:54-64.

20. Romeyke T, Stummer H. Evidence-based complementary and alternative medicine in inpatient care: take a look at Europe. J Evid Based Complementary Altern Med 2015;20:87-93.

21. Cramer H, Lauche R, Moebus S, et al. Predictors of health behavior change after an integrative medicine inpatient program. Int J Behav Med 2014;21:775-83.

22. Tsang RC, Tsang PL, Ko CY, et al. Effects of acupuncture and sham acupuncture in addition to physiotherapy in patients undergoing bilateral total knee arthroplasty - a randomized controlled trial. Clin Rehabil 2007;21:719-28.

23. Kielczynska BB, Kligler B, Specchio E. Integrating acupuncture in an inpatient setting. Qual Health Res 2014;24:1242-52.

24. Shere-Wolfe KD, Tilburt JC, D'Adamo C, et al. Infectious diseases physicians' attitudes and practices related to complementary and integrative medicine: results of a national survey. Evid Based Complement Alternat Med 2013;2013:294381.

25. van Vliet $\mathrm{M}$, Jong $\mathrm{M}$, Busch $\mathrm{M}$, et al. Attitudes, beliefs, and practices of integrative medicine among nurses in the Netherlands. $J$ Holist Nurs 2015;33:110-21.

26. Upsdell M, Jaye $\mathrm{C}$. Engaging with complementary and alternative medicine in general practice. J Prim Health Care 2011;3:29-34.

27. Grant SJ, Bensoussan A. The process of care in integrative health care settings-a qualitative study of US practices. BMC Complement Altern Med 2014;14:410.

28. Skovgaard L, Haahr N, Bjerre L, et al. Types of treatment collaboration between conventional and alternative practitionersresults from a research project at a Danish MS hospital. Int $J$ Integr Care 2010;10:e119.

29. Trail-Mahan T, Mao CL, Bawel-Brinkley K. Complementary and alternative medicine: nurses' attitudes and knowledge. Pain Manag Nurs 2013;14:277-86.

30. Shorofi SA, Arbon P. Nurses' knowledge, attitudes, and professional use of complementary and alternative medicine (CAM): a survey at five metropolitan hospitals in Adelaide. Complement Ther Clin Pract 2010;16:229-34.

31. DeKeyser FG, Bar Cohen B, Wagner N. Knowledge levels and attitudes of staff nurses in Israel towards complementary and alternative medicine. J Adv Nurs 2001;36:41-8.

32. Holroyd E, Zhang AL, Suen LK, et al. Beliefs and attitudes towards complementary medicine among registered nurses in Hong Kong. Int J Nurs Stud 2008;45:1660-6.

33. Rojas-Cooley MT, Grant M. Complementary and alternative medicine: oncology nurses' knowledge and attitudes. Oncol Nurs Forum 2009:36:217-24.

34. Fletcher CE, Mitchinson AR, Trumble EL, et al. Perceptions of providers and administrators in the Veterans Health Administration regarding complementary and alternative medicine. Med Care 2014;52(Suppl 5):S91-6.

35. Tovey P, Broom A. Oncologists' and specialist cancer nurses' approaches to complementary and alternative medicine and their impact on patient action. Soc Sci Med 2007;64:2550-64.

36. Flannery MA, Love MM, Pearce KA, et al. Communication about complementary and alternative medicine: perspectives of primary care clinicians. Altern Ther Health Med 2006;12:56-63.

37. Ge J, Fishman J, Vapiwala N, et al. Patient-physician communication about complementary and alternative medicine in a radiation oncology setting. Int J Radiat Oncol Biol Phys 2013;85: e1-6.

38. Hendershot KA, Dixon M, Kono SA, et al. Patients' perceptions of complementary and alternative medicine in head and neck cancer: a qualitative, pilot study with clinical implications. Complement Ther Clin Pract 2014;20:213-18.

39. Wynia MK, Eisenberg DM, Wilson IB. Physician-patient communication about complementary and alternative medica therapies: a survey of physicians caring for patients with human immunodeficiency virus infection. J Altern Complement Med 1999;5:447-56.

40. Shelley BM, Sussman AL, Williams RL, et al. 'They Don't ask me so I Don't tell them': patient-clinician communication about traditional, complementary, and alternative medicine. Ann Fam Med 2009;7:139-47.

41. Sawni A, Thomas R. Pediatricians' attitudes, experience and referral patterns regarding complementary/alternative medicine: a national survey. BMC Complement Altern Med 2007;7:18.

42. Lee RT, Barbo A, Lopez G, et al. National survey of US oncologists' knowledge, attitudes, and practice patterns regarding herb and 
supplement use by patients with cancer. $J$ Clin Oncol 2014;32:4095-101.

43. Milden SP, Stokols D. Physicians' attitudes and practices regarding complementary and alternative medicine. Behav Med 2004;30:73-82.

44. Furlow ML, Patel DA, Sen A, et al. Physician and patient attitudes towards complementary and alternative medicine in obstetrics and gynecology. BMC Complement Altern Med 2008;8:35.
45. Gallinger ZR, Nguyen GC. Practices and attitudes toward complementary and alternative medicine in inflammatory bowel disease: a survey of gastroenterologists. J Complement Integr Med 2014;11:297-303.

46. Wahner-Roedler DL, Lee MC, Chon TY, et al. Physicians' attitudes toward complementary and alternative medicine and their knowledge of specific therapies: 8-year follow-up at an academic medical center. Complement Ther Clin Pract 2014;20:54-60. 